\title{
Reliability Analysis of Different Cell Configurations of Lithium ion battery Pack
}

\author{
Md. Nahian Al Subri Ivan, Sujit Devnath, Rethwan Faiz and Kazi Firoz Ahmed
}

\begin{abstract}
To infer and predict the reliability of the remaining useful life of a lithium-ion (Li-ion) battery is very significant in the sectors associated with power source proficiency. As an energy source of electric vehicles $(\mathrm{EV})$, Li-ion battery is getting attention due to its lighter weight and capability of storing higher energy. Problems with the reliability arises while li-ion batteries of higher voltages are required. As in this case several li-ion cells are connected in series and failure of one cell may cause the failure of the whole battery pack. In this paper, Firstly, the capacity degradation of li-ion cells after each cycle is observed and secondly with the help of MATLAB 2016 a mathematical model is developed using Weibull Probability Distribution and Exponential Distribution to find the reliability of different types of cell configurations of a non-redundant li-ion battery pack. The mathematical model shows that the parallel-series configuration of cells is more reliable than the series configuration of cells. The mathematical model also shows that if the discharge rate (C-rate) remains constant; there could be an optimum number for increasing the cells in the parallel module of a parallel-series configuration of cells of a non-redundant li-ion battery pack; after which only increasing the number of cells in parallel module doesn't increase the reliability of the whole battery pack significantly.
\end{abstract}

Keywords-Weibull distribution, Exponential distribution, maximum likelihood estimation, shape parameter, scale parameter, rate parameter.

\section{INTRODUCTION}

The use of lithium ion batteries is widespread in powering laptop computers, mobile phones, cameras and many more household electronics and transport vehicles because of their characteristics of high energy density [1], high power density and long cycle life. Except these li-ion batteries are light in weight when compared to other forms of rechargeable cells. Users want long lasting battery life which accounts for the usability of an electronic device which is outright dominated by the amount of charge which is susceptible to storage or its battery capacity. The earliest [2], Eagle-Picher has a welldeveloped, successful history of manufacturing cells and batteries for space programs around the world. Specific technical challenges include the ability of lithium-ion secondary

Md. Nahian Al Subri Ivan is an Assistant Professor of the Department of EEE, American International University - Bangladesh, 408/1, Kuratoli, Khilkhet, Dhaka-1229, Bangladesh. Email: nahian.ivan@aiub.edu

Sujit Devnath completed B.Sc in EEE from American International University-Bangladesh (AIUB), Dhaka-1213, Bangladesh. Email: sujit09devnath@gmail.com

Rethwan Faiz is an Assistant Professor of the Department of EEE, American International University - Bangladesh, 408/1, Kuratoli, Khilkhet, Dhaka-1229, Bangladesh. Email: rethwan_faiz@aiub.edu Kazi Firoz Ahmed is a Senior Assistant Professor of the Department of EEE, American International University - Bangladesh, 408/1, Kuratoli, Khilkhet, Dhaka-1229, Bangladesh. Email: k.firoz@aiub.edu cells to gain the longer cycle life, which is required to use on high reliability spacecraft, and the difficulties in scaling up cell technology to larger capacities required for spacecraft power systems [2].

The reliability of a battery clarifies its ability to perform its intended function. In terms of improvement of the reliability of the battery it is very important to clearly understand the mechanism of capacity degradation pattern of li-ion cells and reasons influencing factors of degradation. As sometimes due to the degradation of anode upon cycling and safety issues prevent the manufacturer from commercialization of li-ion cells [3]. Hence after comprehending the material's degradation pattern a designer can make batteries that have both high capacity and longer cycle life. In reference paper [1], it is found that at ambient temperature charge condition has more influence on the cycle life of the li-ion cell than discharge condition. It is also found that the cycling causes capacity degradation at an enhanced rate than storage and the loss of capacity of li-ion cell on storage has both reversible and irreversible components [4]. Temperature plays an important role in capacity degradation while storing or cycling as increasing temperature causes capacity degradation [4]. On the other hand, in case of automotive $\mathrm{LiFePO}_{4}$ li-ion battery it was found that at lower temperature $\left(0^{\circ} \mathrm{C}\right.$ and $\left.-10^{\circ} \mathrm{C}\right)$ capacity and power fading is more severe after 600 cycle [5]. Hence to save the li-ion cells from capacity degradation, an optimum temperature should be selected while storing and cycling to attain better performance as well as better reliability of li-ion cell. The tensile and compressive stress due to lithium intercalation and de-intercalation is also important for investigation as this can also improve the rate capacity and cyclic life of a battery [6]. Except these, methods for estimating total capacity of cells and analyzing capacity degradation as well as capacity fade prediction model of cells have been presented by the many researchers [7-9] which may play a vital role in estimating and predicting the reliability of li-ion battery pack.

The usability of battery in electric vehicles $(\mathrm{EV})$ is very usual in the worldwide market and the design of the batteries are such that the driving range can be of $100 \mathrm{~km}$ per charge [10]. Applications of the Li-ion battery pack in EVs are challenging as several li-ion cells are connected in series or parallel-series configuration to provide higher voltage [11]. Based on the ageing or life cycle of individual cells, the life span of the battery pack can be estimated. Cells connected in any kind of series configuration may fail as the failure of one cell or one series connection can hamper the operation of the whole battery pack and hence it's obvious that the worst cell determines the performance of the whole battery pack [12]. Whereas a parallelseries combination ensures more reliability as cells connected in parallel arrays which in turn connected in series, can still operate 
with the desired voltage if one cell in parallel connection fails completely but the battery will definitely lose some capacity. Another way to increase reliability is to make a redundant system where the failed cell can be bypassed using switching. [13]. In this paper a non-redundant battery pack is considered for mathematical modeling and reliability analysis.

Now days the electric three wheelers are increasing in Bangladesh; which use lead-acid batteries as power source. These Lead acid batteries are comparatively cheaper and safer than $\mathrm{Li}$-ion batteries. But in case of performance and weight Liion batteries are far more superior to conventional Lead acid batteries. For electric vehicle; the weight of the battery pack has an impact on the total weight of the vehicle itself and more weight means more torque as well as more currents. Hence if the conventional lead acid batteries are replaced by the Li-ion battery packs; the performance of the vehicles will improve.

It has been found that different Li-ion cells show different life cycles although they are developed by using the same chemistry by the same manufacturer $[14,15]$ and the life cycle data of Liion cells follows Weibull Distribution [14]. It is also found that mixed Weibull distribution function fits the life cycle data of Liion cells more properly than a single Weibull distribution function [11]. In this paper life cycle data of 50 cells are selected randomly from a life cycle data of 96 cells presented by the researchers [14] and different mix of Weibull distribution functions are used to fit the data and the results are presented. As life cycle testing of a Li-ion cell is very time consuming and costly; in this paper three Li-ion cells are taken into consideration for finding and presenting their life cycle data. Later a $60 \mathrm{~V}$ Li-ion battery pack of different cell configurations are considered, which can replace the conventional lead-acid batteries of electric three wheelers available in Bangladesh. A mathematical model is developed and used to predict the reliability of different cell configuration of a $60 \mathrm{~V}$ non-redundant battery pack.

\section{DESIGN OF A BATTERY PACK}

A battery pack consisting of cells can be arranged in four different combinations (series, parallel, series-parallel and parallel series). In Fig. 1 these combinations are shown. Different ways of calculating the probability of normal state of the battery packs of different series-parallel and parallel-series cell configurations are shown in reference paper [16]; which can be utilized to calculate other cell configuration of li-ion battery packs. While designing a battery pack for electric three wheelers available in Bangladesh; only parallel connection of cells is not sufficient as they use a battery of 60Volts [17]. Research [11] shows that in most of the cases the manufacturer of electric vehicles uses series and parallel-series configuration of li-ion cells to design their battery pack. Hence most commonly used series configuration and parallel-series configuration of cells were considered to check the reliability among the pack models.

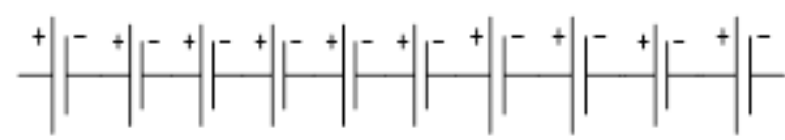

a. Series connection
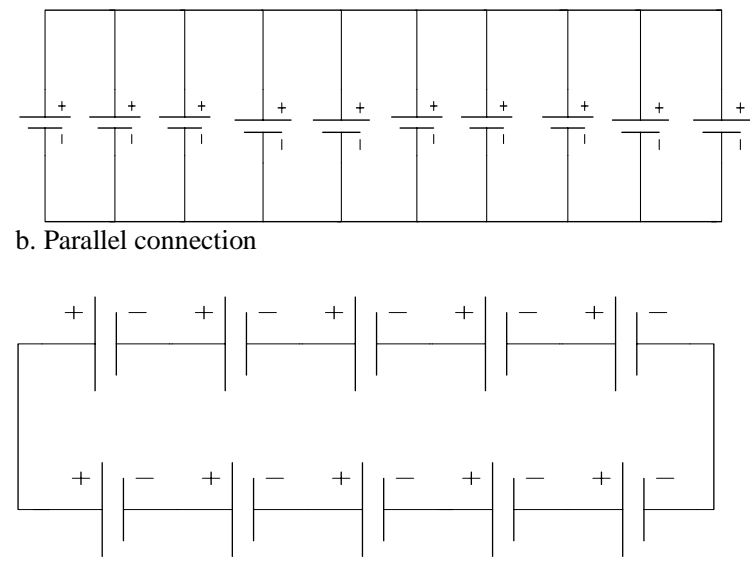

c. Series-parallel connection

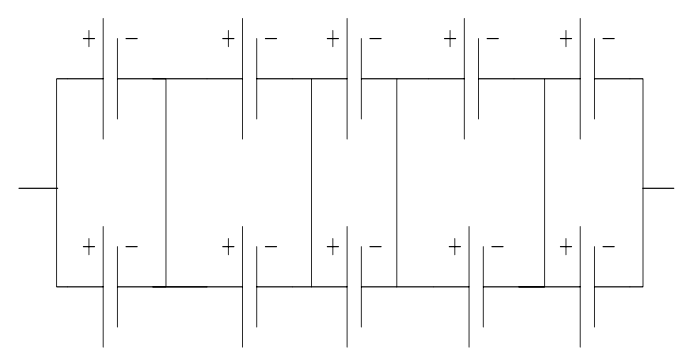

d. Parallel-Series Connection

Fig. 1. Four different battery packs designed with 10 cells in different combinations.

The Li-ion cells available in the market have the nominal voltage ranges of $3.2 \mathrm{~V} \mathrm{[5]} \mathrm{to} 3.85 \mathrm{~V}$ [18] depending on the cell chemistry, where the maximum charge voltage can be of $4 \mathrm{~V}$ to $4.4 \mathrm{~V}[18,19]$. Hence only parallel connection of cells is not considered in this paper to design a battery pack of $60 \mathrm{~V}$. It was observed from the test (table 2) that the life cycle of the li-ion cells is not the same although they are made by using same cell chemistry by the same manufacturer at the same time. Same phenomenon was found for other types of li-ion cell also $[14,15]$. Hence if li-ion cells are connected in series to make a battery pack of higher voltage; the worst cell will determine the overall performance of the battery pack [12]. Therefore, sometimes it is found that a li-ion battery pack is showing less cycle life than the individual li-ion cells [20]. Which is the main drawback of series connected cells. Series-parallel combination of cells also faces same problems as a large number of cells are connected in series. On the other hand, parallel-series combination is proved to be more reliable as in this case if one cell fails after a certain cycle, the whole battery pack doesn't fail and the voltage remain almost the same though the current carrying capacity become less. Parallel-series construction can be a bit costly compared to other configurations, due to the fact that more cells will be required to be connected in parallel to ensure further reliability. Failure of one cell may be dealt with ease without the interruption of electricity but the overall capacity of the battery will decrease. 


\section{METHODOLOGY}

\section{A. Life Cycle Test}

For the experiment; three commercial batteries were selected. The battery had a nominal voltage of $3.7 \mathrm{~V}$ and rated capacity value of $1200 \mathrm{mAh}$. As shown in Fig. 2 the outside casing had a length of $50 \mathrm{~mm}$, a diameter of $14 \mathrm{~mm}$ and a weight of $20 \mathrm{~g}$.

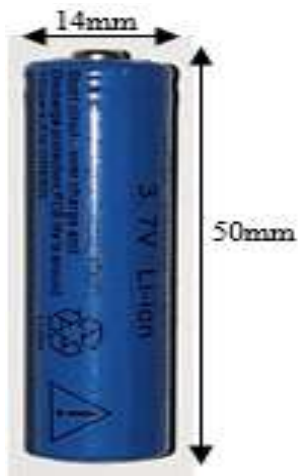

Fig. 2. Lithium-ion battery used in the test.

The batteries were charged at a constant voltage whilst battery input current dropped gradually to less than 50mA.Then the batteries taken under consideration were discharged deliberately at constant current rate $(0.5 \mathrm{C})$ until the nominal voltage came at $2.7 \mathrm{~V}$. The procedure was repeated continuously until the battery's maximum discharge capacity fell to less than $80 \%$ of the initial capacity as none of the batteries showed their rated capacity in the beginning. The best cell shows almost $36 \%$ of its rated capacity at the beginning of the test. Which is not abnormal for poor performance batteries as similar result were presented by other researchers before [19].

TABLE I. THE NUMERICAL DATA OF DISCHARGING THE BATTERIES WERE RECORDED AND SHOWN BELOW.

\begin{tabular}{|l|l|l|}
\hline Battery Samples & $\begin{array}{l}\text { Discharge } \\
\text { Condition }\end{array}$ & Initial Cell Capacity \\
\hline Battery 1 & $0.5 \mathrm{C}$ & $425.2 \mathrm{mAh}$ \\
\hline Battery 2 & $0.5 \mathrm{C}$ & $274.8 \mathrm{mAh}$ \\
\hline Battery 3 & $0.5 \mathrm{C}$ & $165.1 \mathrm{mAh}$ \\
\hline
\end{tabular}

TABLE II. CYCLE LIFE RESULTS FOR TESTED BATTERIES

\begin{tabular}{|l|c|}
\hline Battery samples & $\begin{array}{c}\text { Number of Cycles to Reach 80\% of Initial } \\
\text { Capacity }\end{array}$ \\
\hline Battery 1 & 37 \\
\hline Battery 2 & 53 \\
\hline Battery 3 & 24 \\
\hline
\end{tabular}

The initial capacity and the cycle life of the cells are shown in Table I. and Table II. From the experiment it was found that the total time of discharging the cells are decreasing after each cycles. Initially the best cell takes almost 42.52 minutes to discharge completely and after 37 cycle it takes only 34.09 minutes to discharge and its capacity fells below $80 \%$ of its initial capacity. Similar results are found for other two cells.
The second cell gives more cycles than the first one to reach $80 \%$ of its initial capacity but shows less initial capacity than the first one at the beginning. The third cell shows low initial capacity and less cycles ( 24 cycles) than other two cells. All of these batteries show a very poor performance in case of showing cycle life (less than 60 cycles) and don't show their rated capacity in the test. This may occur due to manufacturing defect or poor storing condition.

\section{B. Reliability Analysis}

The reliability of the battery pack depends on the reliability of the cells. Only three life cycle data is not sufficient to predict the probability distribution of Li-ion cell. Researchers provided [14] the life cycle data of Ninety-six 18650-type lithium iron phosphate cells (1450mAh, $3.2 \mathrm{~V}$ nominal voltage) and it was observed that worst cell had provided 510 cycles whereas the best one showed 1021 cycles [14]. Another research [15] shows the life cycle data of 16 li-ion cells of two different constructions. Two different discharge rate $(1 \mathrm{C}, 0.5 \mathrm{C})$ were used for both types of li-ion cells to find the cycle life and in both cases different cycle life of the cells was found [15]. Previous research [11] proposes that the life cycle data of cells fits well with mixed Weibull distribution.

Hence in this paper life cycle data of 50 cells have been selected randomly from the life cycle data [14] of Ninety-six 18650-type lithium iron phosphate cells and parameter of different mixed Weibull distribution is estimated using maximum likelihood estimation and iteration. After estimating the parameters of different Mixed-Weibull distributions; the curves are plotted to observe and find a more appropriate mix of Weibull distribution that fitted the randomly selected data. the process is shown in Fig. 3.

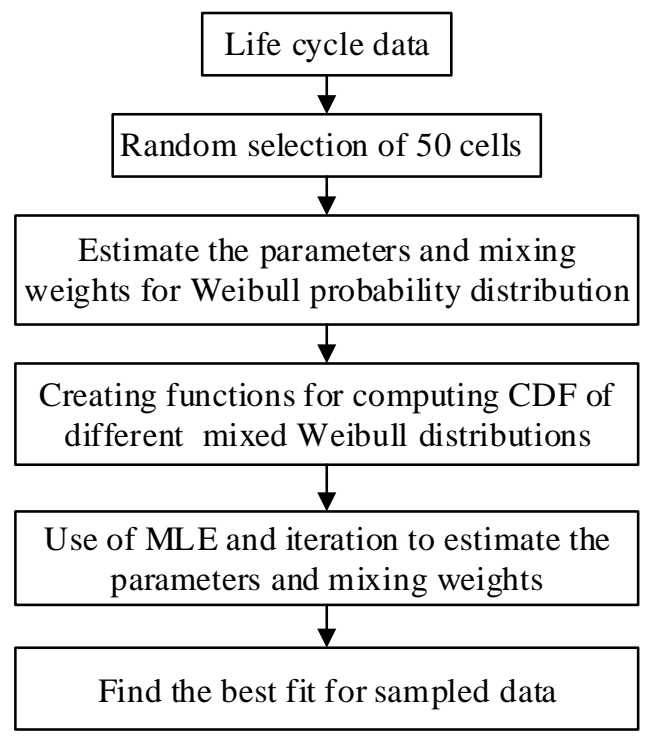

Fig. 3. Process of finding appropriate mix of Weibull distribution for randomly selected life cycle data.

After finding the best fit of mixed Weibull distribution for the data; the probability of failure of cell was estimated. Using the exponential distribution, the probability of failure of weld 
connections were determined and using the mathematical model based on equation 1 the probability of failure of different cell configuration of li-ion battery pack was estimated. A comparison between series connected cell configuration and parallel-series connected cell configuration were presented considering the failure probability of weld connection between the series cells and weld connection of parallel cell modules that are connected in series. The equation can be shown as follows [11].

$F_{c c}(t)=1-\left[1-F_{c e l l}(t)\right]^{n}\left[1-F_{w_{-} c}(t)\right]^{2 n}$

Where

$F_{c_{C}}(t)=$ Failure probability of cell configuration .

$F_{\text {cell }}(t)=$ Failure probability of cell.

$F_{w_{-} c}(t)=$ Failure probability of weld connection.

$\mathrm{n}=$ number of cells or parallel cell modules.

At the end $60 \mathrm{~V}$ li-ion battery pack of different cell configuration was considered for electric three wheelers and their reliability were checked.

\section{Weibull Probability Distribution}

Weibull probability distribution method is one of the methods used by the researchers to estimate the reliability of li-ion cell $[11,14,21$,$] . The method is used for simple interpretation of the$ distribution parameters, their relation to the failure rates $[11,14]$. If a battery pack consists several cells in series or parallel-series configuration; estimating the life time of the whole pack become harder as several failure modes can exist in the system with their own characteristic shape and lifetime, which requires different expression for each failure types and hence Weibull distribution can be a useful tool to check and analyze the reliability of cells of such system [22]. Basically there are three parameters in Weibull distribution. The shape parameter is $\beta$, scale parameter is $\alpha$ and location parameter is $\gamma$. In this paper two parameter Weibull distribution is considered, where location parameter, $\gamma=0$. The cumulative failure distribution function (cdf) can be derived as [21, 23]

$$
\begin{aligned}
& F(t)=1-e^{-\left(\frac{t}{\alpha}\right)^{\beta}} \\
& \ln \left[\ln \left[\frac{1}{1-F(t)}\right]\right]=\beta \ln (t)-\beta \ln (\alpha)
\end{aligned}
$$

Where $\mathrm{F}(\mathrm{x})$ = probability function density;

$\mathrm{t}=$ time

$\beta=$ shape parameter

$\alpha=$ scale parameter

Scale parameter $(\alpha)$ :

Scale parameter is also known as characteristic life. $\alpha$ Is defined by the time when the cumulative failure percent of the population reaches $63.2 \%$ [23].

\section{Shape parameter $(\beta)$ :}

The value of shape parameter $\beta$ reflects the hazard function or the expected failure rate of the Weibull distribution [23-25].
1. A value of $\beta<1$, means the failure rate reduces with time which is normally associated with infant fatality or early failures which may cause due to manufacturing related failures.

2. A value of $\beta=1$, means the failure rate is constant with time. Constant failure rate means the half-life of the product can take place due to random failures.

3. A value of $\beta>1$, means that there is a failure rate increment with time. This occurs when there is aging of the system and that too is likely to fail as time goes on. It is a common co-operator with wear out, fits to the end life of the product.

4. A value of $\beta>10$, means extremely high rate of wear-out failure.

Location parameter $(\gamma)$ :

Weibull distributions have been advanced with more variables to approve for other factors such as location parameter $\gamma$ (gamma) which represents the time delay before the effect of the failures comes off or expected minimum life of a sample [23]. To ignore the complexity in this paper location parameter $\gamma$ is considered as zero.

\section{Expotential Distribution}

The exponential distribution describes the situation wherein the hazard rate is constant [23]. For the evaluation of welded connection between series cells and welded connection between parallel cell modules that are connected in series; an exponential distribution is used. Considering exponential distribution, the cumulative failure distribution can be expressed as $[23,25]$

$$
F(t)=1-e^{-\lambda t}
$$

Where, $\lambda=$ constant hazard rate $\mathrm{t}=$ time

Cumulative failure distribution of exponential distribution is considered for modeling the probability of failure of the welded connections; where $\lambda$ is considered 0.00005 Failures $/ 10^{6} \mathrm{hrs}$ [26].

\section{E. Maximum Likelihood Estimation (MLE)}

For estimating the parameters of Weibull probability distribution; maximum likelihood estimation system provides better result [27]. Maximum likelihood function is the product of individual probability density functions which can be written as [27]:

$$
L=\prod_{i=1}^{n} f\left(t_{i}\right)
$$

The likelihood function for two parameter Weibull distribution can be written as [14]:

$$
L=\prod_{i=1}^{n}\left(\frac{\beta}{\alpha}\right)\left(\frac{t_{i}}{\alpha}\right)^{\beta-1} e^{-\left(\frac{t_{i}}{\alpha}\right)^{\beta}}
$$


The equation of maximum likelihood estimators $\hat{\alpha}, \hat{\beta}$ of $\alpha$ and $\beta$ can be written as [24]

$$
\begin{gathered}
\hat{\alpha}=\left(\frac{1}{n} \sum_{i=1}^{n} x_{i}^{\widehat{\beta}}\right)^{1 / \widehat{\beta}} \\
\hat{\beta}=\left[\left(\sum_{i=1}^{n} x_{i}^{\widehat{\beta}} \log x_{i}\right)\left(\sum_{i=1}^{n} x_{i}^{\widehat{\beta}}\right)^{-1}-\frac{1}{n} \sum_{i=1}^{n} \log x_{i}\right]^{-1}
\end{gathered}
$$

Where $\mathrm{x}_{1}, \mathrm{x}_{2} \ldots \ldots \mathrm{n}$ are $\mathrm{n}$ independent observations from the two parameter Weibull distribution. The target for the research is to find a good estimation of shape parameter and scale parameter of Weibull distribution for randomly selected samples of 50 li-ion cells.

\section{EXPERIMENTAL RESULTS AND ANALYSIS}

To check the distribution, life cycle data of fifty cells were selected randomly from the life cycle data of 96 cells presented by the researchers [14]. From the analysis it was found that the randomly selected life cycle data don't follow simple Weibull distribution properly; but it follows mixed Weibull distribution as stated by the researchers [11]. For analysis three different functions were generated using MATLAB 2016; whereas the first function checks if the data follows mixture of two Weibull distribution or not. Similarly, the second and third function check if the data follows mixture of three Weibull distribution and mixture of four Weibull distribution or not. For generating these functions some important built-in functions of MATLAB 2016 are used.

For getting the cumulative distribution function, 'wblcdf' function is used. For initial estimation of the parameters of Weibull distribution 'wblfit' function was used. Finally, maximum likelihood estimation (MLE) and iteration method is used to estimate all the parameters of mixed Weibull distribution. For maximum likelihood estimation 'mle' function of MATLAB 2016 was used by providing conditions. From the analysis it was found that mixture of three Weibull distribution shows good fit for randomly selected life cycle data of 50 cells. After selecting data randomly and arranging them in ascending order; the parameter for single Weibull distribution was estimated and the curve is plotted which is shown in Fig. 4. But it was found that single Weibull distribution is not the best fit for the randomly selected data. Hence for those data, parameters are estimated for mixture of two, mixture of three and mixture of four Weibull distribution using MLE method and after that the curves are being plotted, which is shown in Fig. 5, Fig. 6 and Fig. 7. It can be seen from the figures that best fit was provided by the mixture of three Weibull distribution. The parameters for mixture of three Weibull distribution are shown in the Table III

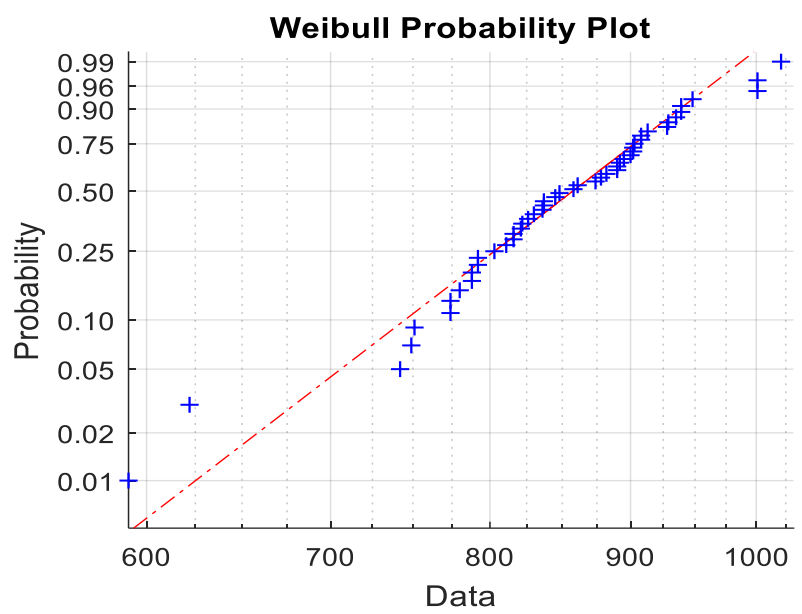

Fig. 4. Representation of single Weibull distribution

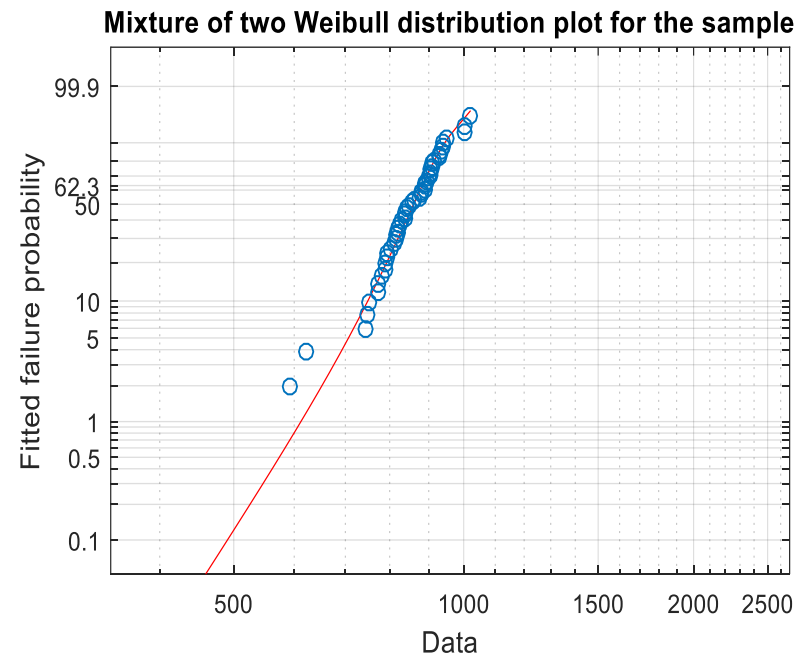

Fig.5. Representation of two Weibull distribution

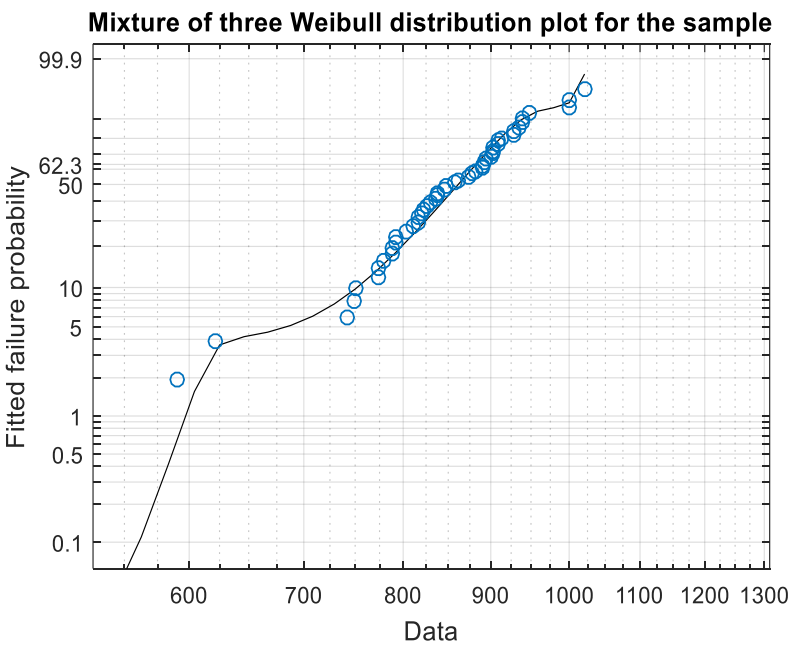

Fig. 6. Representation of three Weibull distribution 


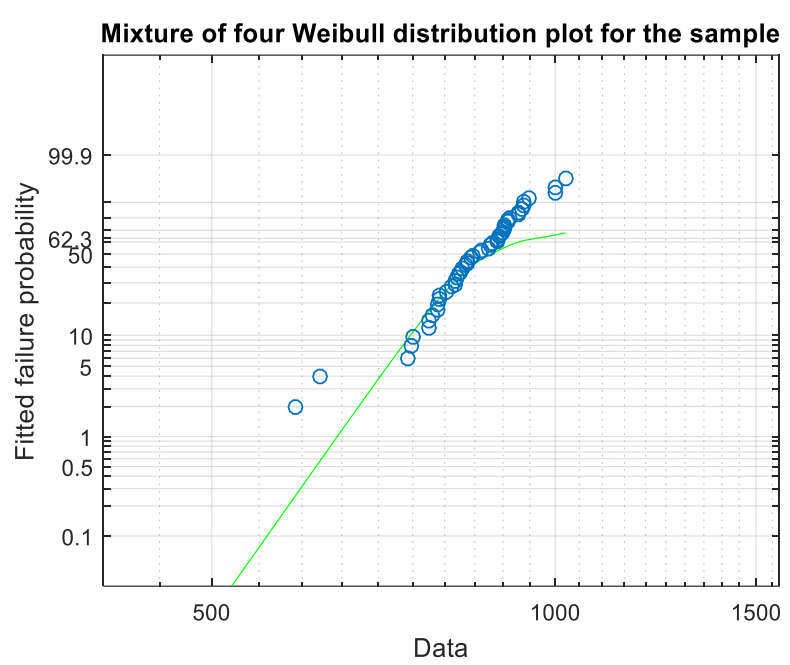

Fig. 7. Representation of four Weibull distribution

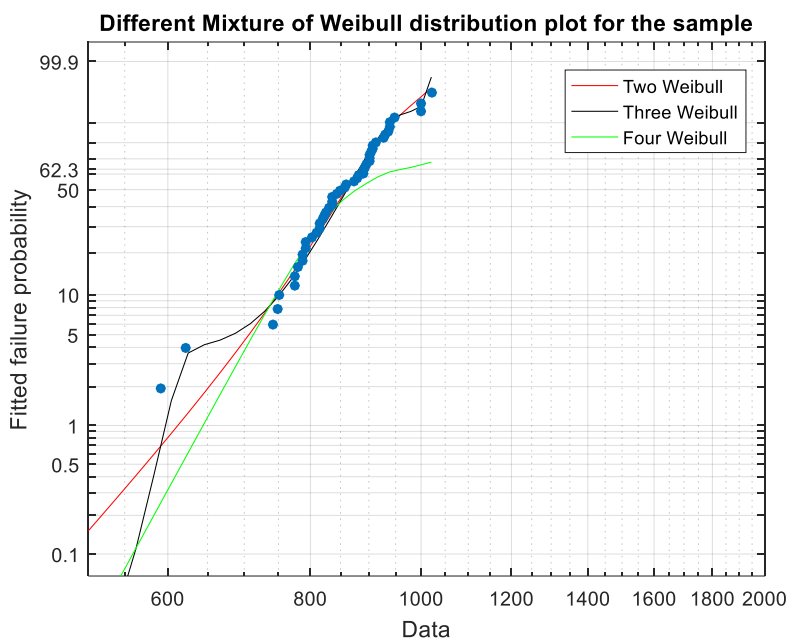

Fig. 8. Representation of three different mixtures of Weibull distributions

TABLE III. SCALE PARAMETERS ( $\boldsymbol{\alpha})$ AND SHAPE PARAMETERS $(\boldsymbol{\beta})$ OF MIXTURE OF THREE WEIBULL DISTRIBUTION

\begin{tabular}{|c|c|c|c|c|c|}
\hline $\boldsymbol{\alpha}_{\mathbf{1}}$ & $\boldsymbol{\alpha}_{\mathbf{2}}$ & $\boldsymbol{\alpha}_{\mathbf{3}}$ & $\boldsymbol{\beta}_{\mathbf{1}}$ & $\boldsymbol{\beta}_{\mathbf{2}}$ & $\boldsymbol{\beta}_{\mathbf{3}}$ \\
\hline 878.4631 & 613.9408 & 1012.596 & 16.90604 & 46.78586 & 106.0353 \\
2426786 & 8770557 & 1834642 & 3950648 & 5743805 & 6738924 \\
1 & 9 & 1 & 8 & 6 & 1 \\
\hline
\end{tabular}

From Table III. it can be seen that every time the value of $\beta$ is greater than 10; which indicates wear-out failures of cells. Fig. 8 shows all the plots found from the mixture of two, three and four Weibull distributions together for better understanding of the best fit. Data were selected randomly several times and every time, mixture of three Weibull distribution shows good result for fifty randomly selected data.

The failure probability of cells is obtained considering the cumulative distribution function (CDF) of mixture of three Weibull distribution. The failure probability of welded connection is obtained by using exponential distribution considering constant hazard rate. After that by using the mathematical model; probability of failure of whole battery pack of series cell configuration was obtained.
In case of parallel-series configuration of cells, the average life cycle of cells presented in each parallel module was obtained; which also followed mixture of three Weibull distribution. After getting the CDF for parallel-series connection of cells; the probability of failure of welded connection is considered and the failure probability of parallel-series combination of cells was obtained by using the mathematical model. The failure probability of series configuration (19 cells connected in series; $1 \mathrm{p} 19 \mathrm{~s})$ and parallel-series configuration ( 2 cells are connected in parallel to create a module and 19 such modules are connected in series; 2p19s) of cells are presented in Fig. 9. From Fig. 9 it can be seen that 2p19s provided better reliability than 1p19s system. Here it should be mentioned that for both case the time to discharge both battery packs is considered 6 hours/cycle (constant); which is the estimated average running time per day for electric three wheelers available in Bangladesh.

Similar simulation was done for 50p19s and 100p19s system using the developed mathematical model and considering same time for discharging (6hrs/cycle). the result is presented in Fig. 10. From the result shown in Fig. 10 it can be said that 100p19s provided little bit better result than 50p19s. But 100p19s cell configuration requires twice the numbers of cells than 50p100s system. So it can be said that if time required to discharge the whole battery remains same (fixed discharge rate) for a nonredundant battery pack, only by increasing the number of cells in a parallel module of a parallel-series cell configuration does not increase the reliability of whole battery pack significantly. Hence if discharge rate is same for a non-redundant battery pack; an optimum number of cells should be considered in the parallel module of parallel-series cell configuration, else the design would not be economically feasible.

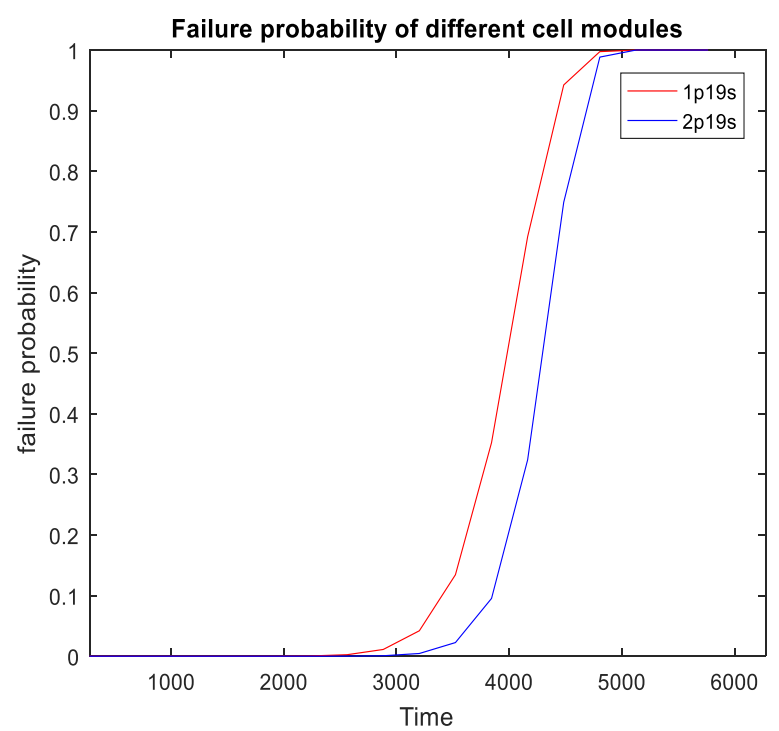

Fig. 9. Probability of failure of series (1p19s) cell configuration and parallelseries cell $(2 \mathrm{p} 19 \mathrm{~s})$ configuration. 


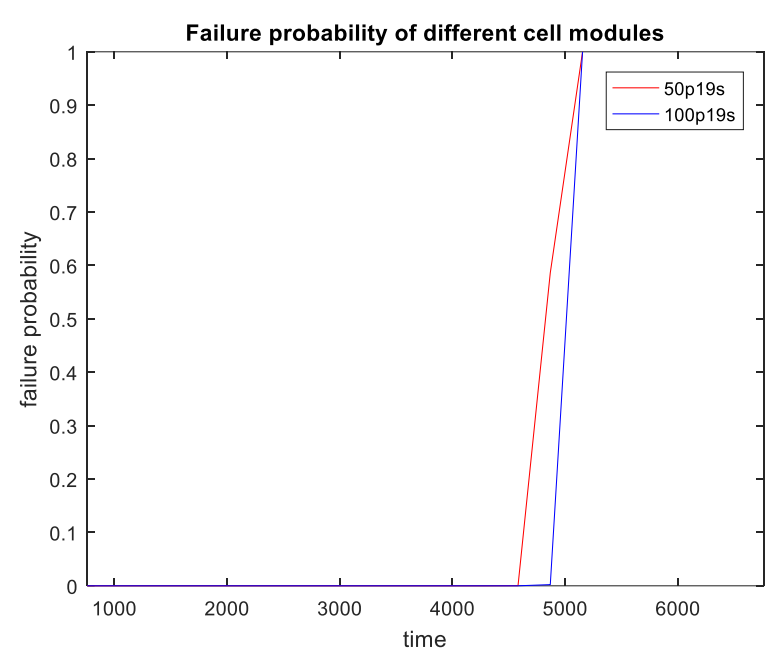

Fig. 10. Probability of failure of two different parallel-series cell (50p19s and 100 p19s) configurations

\section{CONCLUSION}

In this work, first of all the capacity fading of three li-ion cells were observed which are available in the market. All three cells failed to show their rated capacity. A mathematical model for non-redundant cell modules of $60 \mathrm{~V}$ battery pack is presented in this paper and simulation for 4 different cell configurations are done using the mathematical model considering same discharge rate (C-rate) for all battery packs. From the simulation it was found that parallel-series configuration of cells is better than series configurations of cells. This paper considers a nonredundant battery pack for parallel-series configurations which means if any cells in a parallel module failed, the capacity of the whole battery will decrease and it was found that if discharge rate remains same only increasing the cells in parallel module of parallel-series configuration does not increase reliability significantly. This problem can be solved by making a redundant battery pack which may consists of some extra batteries as backup in the parallel module and a switching system. The switching system may be able to by-pass the failed cell and replace it with the cell kept in the battery pack as backup. In this situation the reliability of the battery pack will become higher but at the same time the cost will be increased for the additional cells and switching system. It should be kept in mind that the reliability of such redundant battery pack also depends on the reliability of switching system; which may create a scope for further research.

\section{References}

[1] S.S. Choi, H. S. Lim, "Factors that affect cycle-life and possible degradation mechanisms of a Li-Ion cell based on LiCo02" Journal of Power Sources, Vol. 111, pp. 130-136, 2002.

[2] Curtis T. Martin, Chad 0. Kelly, H. Dwayne Friend, Casey Keen, and Shellie L. Wilson, "Lithium-ion Battery Development at Eagle-Picher", 1999 IEEE

[3] R. Elazari, G. Salitra, G. Gershinsky, A. Garsuch, A. Panchenko D.Aurbach, "Rechargeable Iithiated siliconsulfer(SLS) battery prototypes",Electrochemistry Communications vol 14 (2012) 21-24

[4] Spotnitz R. "Simulation of capacity fade in lithium-ion batteries", J Power Sources 2003; 113(1):72-80.

[5] Zhang Y, Wang C, Tang X. "Cycling degradation of an automotive LiFePO4 lithium-ion battery", J Power Sources 2011; 196(3):1513-20.
[6] S-I Pyun, J-Y Go, T -S Jang, “An investigation on intercalation-induced stresses generated during lithium transport through Li $1.8 \mathrm{Co} 02 \mathrm{flm}$ electrode using a laser beam deflection method", Electrochimica Acta vol 49 (2004) pp 4477-4486

[7] Plett GL. "Recursive approximate weighted total least square estimation of battery cell total capacity", J Power Sources 2011; 196(4):2319-31.

[8] Stamps AT, Holland CE, White RE, Gatzke EP. "Analysis of capacity fades in a lithium-ion battery", J Power Sources 2005; 150:229-39.

[9] Ramadass P, Haran B, White R, Popov BN, "Mathematical modeling of the capacity fade of li-ion cells", J Power Sources 2003; 123(2):230-40.

[10] K.T. Chau and Zheng Wang. "Overview of power electronic drives for electric vehicles", HAIT Journal of Science and Engineering B, Volume 2, Issues 5-6, pp. 737-761

[11] Susanne Rothgang, Thorsten Baumhöfer, Dirk Uwe Sauer, "Necessity and methods to improve battery lifetime on system level", EVS28, KINTEX, Korea, may 3-6, 2015.

[12] Thorsten Baumhofer, Manuel Bruhl, Susanne Rothgang, Dirk Uwe Sauer, "Production caused variation in capacity aging trend and correlation to initial cell performance", journal of power source 247 (2014) 332-338.

[13] Antonio Manenti, Andrea Abba, Alessandro Merati, Sergio M. Savaresi, "A New BMS Architecture Based on Cell Redundancy". IEEE Transactions on Industrial Electronics, Vol. 58, No. 9, September 2011

[14] Li Ran, Wu jun-feng, Wang Hai-ying, Guo jian-ying, Li Ge-chen, "Reliability assessment and failure analysis of lithium-ion phosphate batteries", R.Li et al/information sciences 259 (2014) 359-368.

[15] Nick Williard, Wei He, Dr. Michael Ostennan, Professor. Michael Pecht, "Reliability and Failure Analysis of Lithium Ion Batteries for Electronic Systems", 2012 International Conference on Electronic Packaging Technology \& High Density Packaging 978-1-4673-1681-1112, IEEE.

[16] ZhitaoLiu, CherMing Tan, Feng Leng. Z. Liu, "A reliability-based design concept for lithium-ion battery pack in electric vehicles" et al. / Reliability Engineering and System Safety 134 (2015) 169-177.

[17] Md.Zulkefa Rian ,Dr. A. N. M. Mizanur Rahman, "Study on Power Consumption and Social Aspects of Battery Operated Auto-rickshaw", ICMIEE-PI-140399, 2014 Khulna, BANGLADESH.

[18] https://batteryuniversity.com/learn/article/confusion_with_voltages

[19] Valentin Muenzel, Anthony F. hollenkamp, Anand I. bhatt, Julian de hoog, Marcus brazil, Doreen A. Thomas, and Iven Mareels, "A comparative testing study of commercial 18650-format lithium-ion battery cells", Journal of the electrochemical society, 162 (8) A1592A1600 (2015).

[20] Long Zhou, Yuejiu Zheng, Minggao Ouyang, Languang Lu, "A study on parameter variation effects on battery packs for electric vehicles". Journal of Power Sources 364 (2017), 242-252

[21] Farnaz Ganjeizadeh, Thananan Tapananon, Howard Lei, "Predicting Reliability of Lithium Ion Batteries”. IJERT, Issn: 2278-0181, Vol.3 Issue 8, 10-2014.

[22] E. Suresh Kumar1, Dr. Bijan Sarkar2, "Improvement of Life Time and Reliability of Battery". International Journal of Engineering Science \& Advanced Technology, Volume-2, Issue-5, 1210 - 1217

[23] PATRICK D. T. O'CONNOR, ANDRE KLEYNER, "Practical Reliability Engineering”, Fifth Edition, A John Wiley \& Sons, Ltd., Publication

[24] Chin-Diew Lai,D.N. Pra Murthy, Min Xie, "Weibull Distributions and Their Applications", springer handbook, MS ID: hb06-a2, 4-11-2005

[25] Roy Billinton, Ronald N. Allam, "Reliability evaluation of engineering systems concepts and techniques", $2^{\text {nd }}$ edition.

[26] Military Handbook Reliability Prediction of Electronic Equipment MilHdbk-217f Bef1991superseding Mil-Hdbk-217e, Notice 12 J8nwry 1990

[27] R. Luus, M. Jammer, "Estimation of parameters in 3-parameter Weibull probability distribution functions", Hungarian journal of industrial chemistry vesprem, vol 33(1-2), pp (69-73), 2005 


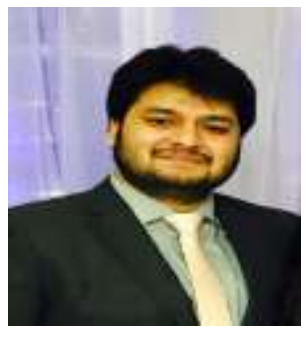

Md. Nahian Al Subri Ivan received B.Sc. in Electrical \& Electronic Engineering (EEE) in 2011 and MBA in Operations Management in 2013 from American International University-Bangladesh (AIUB). He received M.Sc. in Electrical Power Engineering From RWTH Aachen University, Germany in 2015.Currently he is working as an Assistant Professor at the Department of EEE in American International University-Bangladesh. His research interests include Renewable Energy Technology, Energy Storage System and Technology, Systems Reliability and Electric Vehicles.

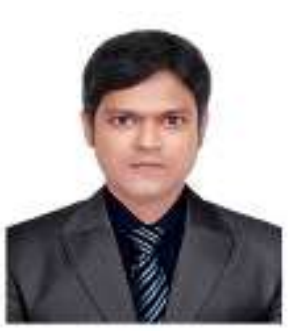

Sujit Devnath received B.Sc. in Electrical \& Electronic Engineering (EEE) from American International University-Bangladesh (AIUB) in 2016. Currently he is pursuing his M.Sc. in Engineering from AIUB. His research interests include Battery System, Renewable Energy Technology, Power System Analysis, Power System Protection, Control and Optimization.

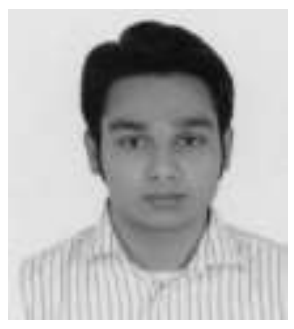

Rethwan Faiz received his B.Sc in Electrical and Electronic Engineering and MBA from American International University-Bangladesh (AIUB), in 2011 and 2014 respectively. At present he is working at AIUB as an Assistant Professor in the Department of Electrical and Electronic Engineering. He was awarded Summa Cum Laude for his outstanding result in his bachelor studies. His research interest includes Electric Vehicles, Wireless Sensor Network, Biomedical Engineering and Nano electronics.

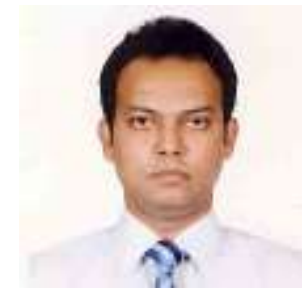

Kazi Firoz Ahmed is recently working as a Senior Assistant Professor to the Department of EEE at American International University- Bangladesh (AIUB). He has been teaching and doing his research works in this university since 2010 . In AIUB he is teaching undergraduate students and conducting various types of research

Works with undergraduate and postgraduate students. His field of interest is in Power system engineering, renewable energy, machines, and drives. He has completed his Bachelor's degree from Islamic University of Technology (IUT) in 2005 from the Department of Electrical and Electronic Engineering. He has also completed his Master's degree from AIUB in 2012. Currently, he is pursuing his Ph.D. degree at Islamic University of Technology (IUT). 